\title{
Effects of lumbar myelography on subarachnoid pressure and cardiorespiratory parameters in healthy sheep ${ }^{1}$
}

\author{
Bruno W. Minto², Luciane R. Mesquita ${ }^{3 *}$ (D) , João A.L. Souza², Gabriela M. Bueno², \\ Luís G. Faria ${ }^{2}$, Fernando Y.K. Kawamoto², Diego Yamada ${ }^{2}$ and Luis C. Marques ${ }^{2}$
}

\begin{abstract}
Minto B.W., Mesquita L.R., Souza J.A.L., Bueno G.M., Faria L.G., Kawamoto F.Y.K., Yamada D. \& Marques L.C. 2021. Effects of lumbar myelography on subarachnoid pressure and cardiorespiratory parameters in healthy sheep. Pesquisa Veterinária Brasileira 41:e06672, 2021. Departmento de Cirurgia e Anestesiologia Veterinária, Faculdade de Medicina Veterinária e Zootecnia, Universidade Estadual Paulista "Júlio de Mesquita Filho", Rua Prof. Dr. Valter Corrêa s/n, Botucatu, SP 18618-681, Brazil. E-mail: Irmesquita@yahoo.com.br

The purpose of this study was to evaluate the effects of lumbar myelography on subarachnoid pressure, cardiorespiratory parameters and pressure-volume index in sheep. Eight sheep were evaluated. The animals were submitted to puncture of the cisterna magna for monitoring of subarachnoid pressure (SaP). Lumbar myelography was performed through applying Iohexol $(0.4 \mathrm{~mL} / \mathrm{kg}) . \mathrm{T}^{\circ} \mathrm{C}, \mathrm{PAS}, \mathrm{PAD}, \mathrm{MAP}$, InspISO, FeISO, SaP and CPP were recorded immediately after anesthetic stabilization (M0), during lumbar puncture (M1), and two, four and six minutes after contrast application (M2, M3 and M4, respectively). Blood pressure initially increased, then decreased, returning to basal level, similarly observed for InspISo and FeISo. The SaP rose initially thereafter remaining stable. Despite of the effect on subarachnoid pressure, lumbar myelography can be considered safe in sheep.
\end{abstract}

INDEX TERMS: Lumbar, myelography, subarachnoid pressure, cardiorespiratory parameter, sheep, neuroradiology, intercranial pressure, ovine, pressure-volume index.

\begin{abstract}
RESUMO.- [Efeitos da mielografia lombar na pressão subaracnoidea e nos parâmetros cardiorrespiratórios em ovelhas saudáveis.] 0 objetivo foi avaliar os efeitos da mielografia lombar na pressão subaracnóidea, parâmetros cardiorrespiratórios e índice pressão-volume em ovinos. Oito ovelhas foram avaliadas. Os animais foram submetidos à punção da cisterna magna para monitoramento da pressão subaracnoidea (SaP). A mielografia lombar foi realizada com a aplicação de Iohexol $(0,4 \mathrm{~mL} / \mathrm{kg})$. Os momentos estudados foram: imediatamente após a estabilização anestésica (M0), durante a punção lombar (M1), dois, quatro e seis minutos após a aplicação do contraste (M2, M3 e M4, respectivamente), para avaliar as seguintes variáveis: $\mathrm{T}^{\circ} \mathrm{C}$, PAS, PAD, MAP, InspISO, FeISO, Sap e CPP. A pressão arterial aumentou inicialmente,
\end{abstract}

\footnotetext{
${ }^{1}$ Received on March 11, 2021.

Accepted for publication on March 24, 2021

${ }^{2}$ Departamento de Clínica Veterinária, Faculdade de Ciências Agrárias e Veterinárias, Universidade Estadual Paulista "Júlio de Mesquita Filho" (Unesp), Via de Acesso Prof. Paulo Donato Castellane, Vila Industrial, Jaboticabal, SP 14884-900, Brazil.

${ }^{3}$ Departamento de Cirurgia e Anestesiologia Veterinária, Faculdade de Medicina Veterinária e Zootecnia (FMVZ), Universidade Estadual Paulista "Júlio de Mesquita Filho" (Unesp), Rua Prof. Dr. Valter Corrêa s/n, Botucatu, SP 18618-681, Brazil. *Corresponding author: lrmesquita@yahoo.com.br
}

depois diminuiu, retornando aos valores iniciais, padrão também observado para o InspISo e o FeISo. O SaP subiu inicialmente, posteriormente, permanecendo estável. A mielografia lombar, apesar de influenciar a pressão subaracnoidea, pode ser considerada segura em ovinos.

TERMOS DE INDEXAÇÃO: Mielografia, lombar, pressão subaracnóidea, cardiorrespiração, ovelhas neurorradiologia, pressão intracraniana, ovinos, índice volume-pressão.

\section{INTRODUCTION}

Myelography is a widespread diagnostic exam in veterinary practice, especially for identifying compressive disorders of spinal cord. The injection of a non-ionic contrast medium into the subarachnoid space can be performed through puncturing the cisterna magna or lumbar region (L5-L6) (Kishimoto et al. 2004).

Despite of modern modalities of diagnostic imaging, such as computed tomography and magnetic resonance imaging, myelography remains important, especially due to its specificity and sensitivity for identifying spinal cord compressions (Arany-Tóth et al. 2012). 
Several complications have been related to this procedure. Epileptic crisis is considered the most prevalent and important one (Barone et al. 2002). Among other causes, the increase of subarachnoid pressure deserves to be highlighted once it can contribute, potentially, to adverse effects (Arany-Tóth et al. 2012).

The pressure-volume index (PVI) is defined as the volume infused in the subarachnoid space necessary for elevating basal intercranial pressure (ICP) by ten times (Marmarou et al., 1978). Its value is influenced principally by four parameters: intercranial complacency, dural sinus pressure, cerebrospinal fluid absorption rate (CSL) and its formation (Silva Jr 2006).

Some studies have attempted to employ PVI to predict the volume of intercranial reserve in patients with severe cranial trauma, in order to level the risk of developing early intercranial hypertension (Marmarou et al. 1978). It should be noted that such trauma provokes an increase in intercranial volume, parenchyma (edema) or blood (venous congestion, hemorrhages), and thus leakage of reserve volume (complacency), finally leading to increase of ICP (Siqueira et al. 2013). In this context, PVI estimates reflect the risk of a worsening clinical signs independent of the ICP value (Maset et al. 1987).

Following this rationale, the introduction of a contrast medium through subarachnoid route during a myelography, will lead to an augmentation of CSL, which can cause ICP increasing, depending on infusion velocity and individual compensatory mechanisms (Avezaat et al. 1979). Reduction of encephalic perfusion can, finally, lead to neurological and systemic alterations (Arany-Tóth et al. 2013).

With the advent of MRI, the clinical relevance of myelography is decreasing, however it is still the most widely used and easily accessible tool in financial terms. There are still authors who report situations of acute spinal cord compression, in which myelography has better diagnostic quality (Robertson \& Thrall 2011). The clinical relevance of the present study is to present more concise data and to make the procedure safe during its performance. The present study aimed to evaluate the effect of lumbar myelography on subarachnoid space pressure, cardiorespiratory parameters, and pressurevolume index in sheep. The hypothesis of the study was that myelography performed by lumbar puncture would result in minor changes in subarachnoid pressure, cerebral perfusion pressure and volume pressure index.

\section{MATERIALS AND METHODS}

Ethics statement. The methodology adopted in this study was approved by the Animal Experimentation Ethics Committee of the "Faculdade de Ciências Agrárias e Veterinárias" of the "Universidade Estadual Paulista "Júlio de Mesquita Filho" (Unesp), Jaboticabal/SP (protocol number 015285/14).

Data collection. Eight females, young adults (aged between two and four years), Santa Inês healthy sheep, weighing $44.7 \mathrm{~kg} \pm 4.4 \mathrm{~kg}$, were used. Neurological examination was performed on all sheep, ruling out neurological changes.

After being submitted to fasting (36 hours for food and 12 for water) all animals received pre-anesthetic medication based on Midazolam (Hipolabor, Belo Horizonte, Brazil) (0.1mg/kg, IM). Fifteen minutes later, they went through anesthetic induction with Propofol (Provive 1\%, Claris Lifesciences Limited, Ahmedabad, India) (4 to $6 \mathrm{mg} / \mathrm{kg}$ ), and orotracheal intubation with a Magill probe (Cirúrgica Fernandes, São Paulo, Brazil). Anesthesia was maintained with Isoflurane (Instituto BioChimico Indústria Farmacêutica Ltda, Rio de Janeiro, Brazil) diluted in oxygen in a calibrated vaporizer (HB Comercial Hospitalar Ltda, São Paulo, Brazil) at 1.2\%. The animals were kept under ventilation with controlled volume and pressure limited to $10-15 \mathrm{cmH}_{2} \mathrm{O}, \mathrm{I}$ : $\mathrm{E}$ ratio of $1: 2$ adjusted to respiratory frequency so that the $\mathrm{EtCO}_{2}$ value would remain between 35 and $45 \mathrm{mmHg}$.

Invasive pressure was measured through a multi-parametric monitor (Dixtal - mod. DX2010, Manaus, Brazil) after catheterization of the medial auricular artery. The inhaled and exhaled Isoflurane concentrations (InspISO and FeISO) were measured by an analyzer of gases (Dixtal mod. DX2010 module gas analyzer, Manaus, Brazil), with the latter being obtained from samples of exhaled air collected at the distal end of the endotracheal tube.

The animals were positioned in right lateral decubitus and flexed head. The atlanto-occipital and lumbar regions were aseptically clipped (Chlorhexidine Degermante 2\% followed by alcoholic Chlorhexidine $0.5 \%$ ). A 22G spinal needle (BD, São Paulo, Brazil) was inserted into the cisterna magna and kept fixed on place during measurements using a sterilized $16 \mathrm{~cm}^{2}$ EVA (Ethyl Vinyl Acetate) support. Afterwards, $4 \mathrm{~mL}$ of CSL was continually discarded, and the needle was coupled to a digital pressure analyzer (Dixtal mod. DX 2010, Manaus, Brazil) by means of an equipment extender prefilled with sterile saline solution.

Lumbar myelography was performed with a $22 \mathrm{G}$ spinal needle inserted between L5 and L6. The iodinated contrast medium (Omnipaque 300mg/mL, GE Healthcare, Shanghai, China) was infused into the subarachnoid space at the rate of $4.1 \mathrm{~mL} / \mathrm{min}$, using an infusion pump (Injectomat Agilia, Fresenius Kabi, Homburg, Germany); the dose of contrast medium was $0.4 \mathrm{~mL} / \mathrm{kg}$.

Assessed data. After anesthetic stabilization, which was considered when the animal had been remained for 10 minutes with the same FeISO, the data were collected at the following moments: immediately after anesthetic stabilization (M0), during lumbar puncture (M1), two minutes after contrast injection (M2), four minutes after contrast injection (M3) and six minutes after contrast injection (M4). Body temperature $\left(\mathrm{T}^{\circ} \mathrm{C}\right)$, respiratory rate $(\mathrm{RR})$, heart rate (HR), systolic blood pressure (PAS), diastolic blood pressure (PAD), mean blood pressure (MAP), oxygen saturation $\left(\mathrm{SpO}_{2}\right)$, expired fraction of carbon dioxide $\left(\mathrm{EtCO}_{2}\right)$, InspISO and FeISO were recorded.

The subarachnoid pressure (SaP) was measured immediately after atlanto-occipital puncture (SaP0), the greatest value during the injection of contrast medium (SaPmax - maximum subarachnoid pressure) and, two (SaP2), four (SaP3) and six (SaP4) minutes after contrast medium injection.

After obtaining the values of SaP and MAP, cerebral perfusion pressure (CPP) was calculated through the following formula: $\mathrm{CPP}=\mathrm{MAP}-$ ICP.

The pressure-volume index was obtained through the formula:

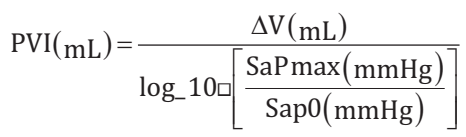

Radiographic analysis. The radiographs of the lumbar vertebral column were obtained using a direct digital X-ray apparatus (Portable DR system PDX-1417, Poskom Co. LCD, Goyang, Korea) in order to evaluate proper injection of the contrast medium into the subarachnoid space.

Statistical analysis. The means of the variables (RR, HR, PAS, PAD, $\mathrm{MAPSpO}_{2}$, $\mathrm{EtCO}_{2}$, InspISO, FeISO, SaP and CPP) were compared with each other between the moments, utilizing the analysis of variables of repeated measures, considering the animals as blocks. For this, a 5\% significance level was adopted. Significant differences between moments was also assessed by linear regression analysis to study the behavior of variables as a function of moments, and to obtain the pressure-volume index (PVI). Furthermore, the degree of association between the referenced variables was evaluated through Pearson's correlation test. 


\section{RESULTS}

Table 1 displays the means, standard deviations and comparisons by Tukey's test, of the variables $\mathrm{T}^{\circ} \mathrm{C}, \mathrm{RR}, \mathrm{HR}, \mathrm{PAS}, \mathrm{PAD}, \mathrm{MAP}$, InsISO, FelSO, SaP, $\mathrm{EtCO}_{2}, \mathrm{SpO}_{2}$ and $\mathrm{CPP}$ at the following moments: M0, M1, M2, M3 and M4. Different letters in a column represent a statistical difference between moments, considering significant differences at a 5\% confidence level.

The $\mathrm{T}^{\circ} \mathrm{C}$ showed a significant decrease comparing moments M0, M1 and M4. However, RR and HR did not differ statistically (Table 1). PAS and PAD behaved in a similar pattern, presenting an increase at moments M1 and M2 when compared to the moment M0 and a decrease between M1, M3, and M4. MAP increased at M2, whereas it showed a decrease at other moments, returning to basal levels. SaP presented a significant increase at the moment M1 followed by a diminution at M2 and reaching basal levels at M3 and M4 (Table 1).
The concentrations of InspISO and FelSO were augmented at $\mathrm{M} 1$ and remained elevated until $\mathrm{M} 4 . \mathrm{EtCo}_{2}$ and $\mathrm{SpO}_{2}$ did not show a statistical difference at any of the moments. As to CPP, it was observed a reduction at M1 in comparison to $\mathrm{M} 0$ and soon after an increase between M2 vs M3 and M4, although these (M2, M3 and M4) were statistically equal to the M0 values (Table 1 ).

The variables $\mathrm{T}^{\circ} \mathrm{C} / \mathrm{RR}, \mathrm{HR} / \mathrm{RR}, \mathrm{RR} / \mathrm{PAS}, \mathrm{RR} / \mathrm{PAD}, \mathrm{RR} / \mathrm{MAP}$, $\mathrm{RR} / \mathrm{CPP}, \mathrm{HR} / \mathrm{SpO}_{2}$, PAD/PAS, PAS/MAP, SaP/PAS, MAP/PAD, $\mathrm{PAD} / \mathrm{SaP}, \mathrm{MAP} / \mathrm{SaP}_{2} \mathrm{EtCO}_{2} / \mathrm{SpO}_{2}$, EtCO $/$ InspISO, FeISO/InspISO and SaP/CPP were evaluated by Pearson's correlation test, considering a correlation significance level to be $5 \%$. These findings are shown in Table 2 which displays the $r$ value, the $p<0.05$ significance level, and the degree of correlation strength, where $r<0.39$ represents a weak correlation, $r>0.4<0.69$ a moderate correlation and $r>0.7<1.0$ evidences a strong correlation.

Table 1. Mean and standard deviation and Tukey's test of body temperature $\left(\mathrm{T}^{\circ} \mathrm{C}\right)$, respiratory rate (RR), heart rate (HR), systolic blood pressure (PAS), diastolic blood pressure (PAD), mean blood pressure (PAM), expired fraction of carbon dioxide

$\left(\mathrm{EtCO}_{2}\right)$, oxygen saturation $\left(\mathrm{SpO}_{2}\right)$, inhaled Isoflurane concentrations (InspISO), exhaled Isoflurane concentrations (FeISO), subarachnoid pressure (SaP) and cerebral perfusion pressure (CPP) of the experimental model of ovine submitted to lumbar

\begin{tabular}{|c|c|c|c|c|c|c|c|c|c|c|c|c|}
\hline & 37.58 & 9.25 & 107.38 & 89.00 & 62.38 & 76.13 & 41.25 & 97.50 & 1.56 & 1.08 & 11.13 & 65.00 \\
\hline M1 & $\begin{array}{c}37.01 \\
( \pm 1.05) \mathrm{B}\end{array}$ & $\begin{array}{c}10.00 \\
( \pm 1.85) \mathrm{A}\end{array}$ & $\begin{array}{c}118.87 \\
( \pm 26.40) \mathrm{A}\end{array}$ & $\begin{array}{c}121.00 \\
( \pm 26.79) \mathrm{C}\end{array}$ & $\begin{array}{c}92.1 \\
( \pm 24.38) \mathrm{C}\end{array}$ & $\begin{array}{c}105.25 \\
( \pm 24.81) \mathrm{B}\end{array}$ & $\begin{array}{c}42.63 \\
( \pm 3.46) \mathrm{A}\end{array}$ & $\begin{array}{c}97.38 \\
( \pm 0.74) \mathrm{A}\end{array}$ & $\begin{array}{c}1.71 \\
( \pm 0.14) \mathrm{B}\end{array}$ & $\begin{array}{c}1.31 \\
( \pm 0.15) \mathrm{B}\end{array}$ & $\begin{array}{c}101.88 \\
( \pm 22.53) \mathrm{C}\end{array}$ & $\begin{array}{c}3.38 \\
( \pm 13.85) \mathrm{C}\end{array}$ \\
\hline M3 & $\begin{array}{c}36.85 \\
( \pm 0.96) \mathrm{BC}\end{array}$ & $\begin{array}{c}9.88 \\
( \pm 1.95) \mathrm{A}\end{array}$ & $\begin{array}{c}108.00 \\
( \pm 21.98) \mathrm{A}\end{array}$ & $\begin{array}{c}100.88 \\
( \pm 18.90) \mathrm{AB}\end{array}$ & $\begin{array}{c}75.38 \\
( \pm 19.28) \mathrm{AB}\end{array}$ & $\begin{array}{c}85.88 \\
( \pm 21.07) A\end{array}$ & $\begin{array}{c}41.13 \\
( \pm 4.32) \mathrm{A}\end{array}$ & $\begin{array}{c}97.00 \\
( \pm 0.92) \mathrm{A}\end{array}$ & $\begin{array}{c}1.76 \\
( \pm 0.14) \mathrm{B}\end{array}$ & $\begin{array}{c}1.31 \\
( \pm 0.14) \mathrm{B}\end{array}$ & $\begin{array}{c}19.13 \\
( \pm 3.44) \mathrm{A}\end{array}$ & $\begin{array}{c}66.75 \\
( \pm 23.34) \mathrm{A}\end{array}$ \\
\hline M4 & $\begin{array}{c}36.83 \\
( \pm 0.97) \mathrm{C}\end{array}$ & $\begin{array}{c}9.88 \\
( \pm 1.95) \mathrm{A}\end{array}$ & $\begin{array}{c}108.25 \\
( \pm 23.37) \mathrm{A}\end{array}$ & $\begin{array}{c}99.38 \\
( \pm 22.26) \mathrm{AB}\end{array}$ & $\begin{array}{c}74.50 \\
( \pm 19.53) \mathrm{AB}\end{array}$ & $\begin{array}{c}85.75 \\
( \pm 20.21) A\end{array}$ & $\begin{array}{c}42.13 \\
( \pm 3.83) \mathrm{A}\end{array}$ & $\begin{array}{c}97.38 \\
( \pm 0.74) \mathrm{A}\end{array}$ & $\begin{array}{c}1.76 \\
( \pm 0.15) \mathrm{B}\end{array}$ & $\begin{array}{c}1.31 \\
( \pm 0.17) \mathrm{B}\end{array}$ & $\begin{array}{c}15.25 \\
( \pm 5.06) \mathrm{A}\end{array}$ & $\begin{array}{c}70.50 \\
( \pm 22.03) \mathrm{A}\end{array}$ \\
\hline
\end{tabular}

$\bar{A}, \mathrm{~B}, \mathrm{C}=$ different letters in the same column indicate statistical difference at $5 \%$ by the Tukey test.

Table 2. Pearson correlation among the variables body temperature $\left(\mathrm{T}^{\circ} \mathrm{C}\right)$, respiratory rate (RR), heart rate (HR), diastolic blood pressure (PAD), mean blood pressure (PAM), expired fraction of carbon dioxide $\left(\mathrm{EtCO}_{2}\right)$, oxygen saturation $\left(\mathrm{SpO}_{2}\right)$, inhaled Isoflurane concentrations (InspISO), exhaled Isoflurane concentrations (FeISO), subarachnoid pressure (SaP) and cerebral perfusion pressure (CPP), exposing the $r$ value of the experimental model of ovine submitted to lumbar myelography and pressure gauging subarachnoid

\begin{tabular}{|c|c|c|c|c|c|c|c|c|c|c|c|c|}
\hline & $\mathrm{T}^{\mathrm{o}}$ & $\mathrm{RR}$ & HR & PAS & PAD & PAM & $\mathrm{EtCO}_{2}$ & $\mathrm{SpO}_{2}$ & InspISO & FeISO & $\mathrm{SaP}$ & $\mathrm{CPP}$ \\
\hline $\mathrm{T}^{\mathrm{o}}$ & 1 & & & & & & & & & & & \\
\hline $\mathrm{RR}$ & $-0.327 * €$ & 1 & & & & & & & & & & \\
\hline HR & -0.286 & $0.538 * \S$ & 1 & & & & & & & & & \\
\hline PAS & 0.133 & $-0.618 * \S$ & -0.032 & 1 & & & & & & & & \\
\hline PAD & 0.209 & $-0.629 * \S$ & -0.091 & $0.932 * \partial$ & 1 & & & & & & & \\
\hline PAM & 0.183 & $-0.683^{*} \S$ & -0.134 & $0.967 * \partial$ & $0.942 * \partial$ & 1 & & & & & & \\
\hline InspISO & 0.051 & 0.174 & 0.009 & 0.104 & 0.117 & 0.050 & $0.414 * \S$ & 0.177 & 1 & & & \\
\hline FeISO & -0.172 & 0.298 & -0.127 & -0.073 & -0.024 & -0.086 & 0.107 & -0.008 & $0.752^{*} \partial$ & 1 & & \\
\hline Sap & -0.070 & 0.011 & 0.167 & $0.536^{*} \S$ & $0.468 * \S$ & $0.505^{*} \S$ & 0.058 & 0.075 & -0.012 & 0.134 & 1 & \\
\hline СРP & 0.206 & $-0.481 * \S$ & -0.286 & 0.045 & 0.106 & 0.103 & -0.054 & -0.173 & 0.049 & -0.213 & $-0.806^{*} \partial$ & 1 \\
\hline
\end{tabular}

$£=$ Weak correlation $r<0.39, \S=$ moderate correlation $r>0.4<0.69, \partial=$ strong correlation $r>0.7<1.0$; ${ }^{*}$ significative values $5 \%$, in these the superscript symbol represents the strength of the correlation. 
The analyzed parameters that presented a weak correlation $(r<0.39)$ and differed statistically were: $\mathrm{T}^{\circ} \mathrm{C} / \mathrm{RR}$ and $\mathrm{HR} / \mathrm{SpO}_{2}$. Those that presented a moderate correlation $(r>0.4<0.69)$ were: HR/RR, RR/PAS, RR/PAD, RR/MAP, RR/CPP, SaP/PAS, $\mathrm{PAD} / \mathrm{SaP}, \mathrm{MAP} / \mathrm{SaP}_{\mathrm{EtCO}} / \mathrm{SPO}_{2}$ and $\mathrm{EtCO}_{2} /$ InsplSO. Yet the parameters with a strong correlation $(r>0.7<1)$ were: PAD/PAS, PAS/MAP, MAP /PAD, FelSO/InsplSO and SaP/CPP (Table 2).

Figure 1 displays the variables HR, MAP, SaP and CPP, together with the lines of polynomial tendencies in order to demonstrate the behavior of these variables at the moments analyzed. It is noted that along with the increase of SaP, there is a rise in MAP together with diminution of CPP, but with $\mathrm{HR}$ remaining practically stable at all moments.

The variables weight, animal length measured from the occipital crista to the iliac tuberosity, volume of contrast infused, PVI, SaP0 and SaPmax, were submitted to calculations of the means and standard deviations, as displayed in Table 3.

The variables, weight, length, volume and PVI were analyzed by Pearson's correlation, and are shown in Table 4, along with the $r$ value and the significance indication of $p<0.05$ and the degree of correlation strength, where $r<0.39$ represents a weak

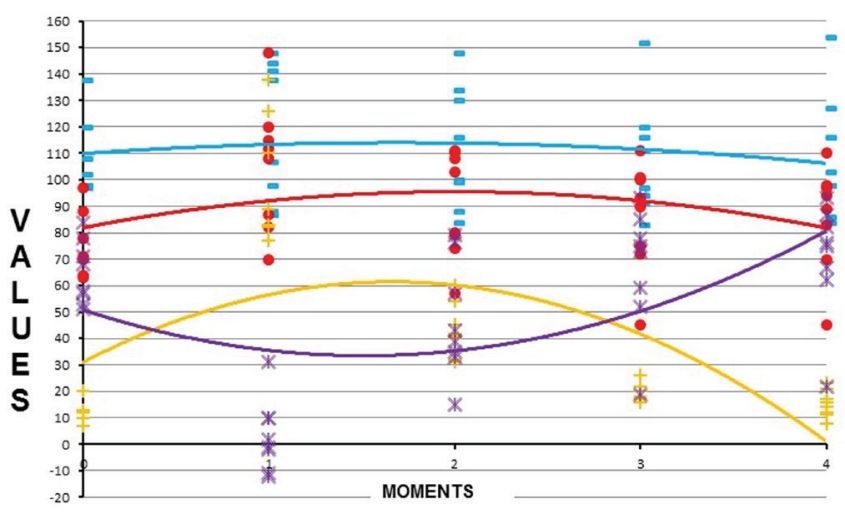

Fig.1. Graphical representation of the polynomial trend line of the variables $\mathrm{HR}=$ heart rate (blue lines and traces), MAP = mean blood pressure (red lines and points), SaP = subarachnoid pressure (yellow lines and cross) and $\mathrm{CPP}=$ cerebral perfusion pressure (purple lines and $\mathrm{X}$ ) of the experimental model of ovine submitted to lumbar myelography and measurement of subarachnoid pressure.

Table 3. Mean and standard deviation of the variables body weight, measured length of nuchal ridge to iliac tuberosity, infused contrast volume, pressure volume-index (PVI), subarachnoid pressure (Sap0) and maximum subarachnoid pressure (SaPmax), obtained from the experimental model of ovine submitted to lumbar myelography and gauging subarachnoid pressure

\begin{tabular}{ccc}
\hline Variable & Mean & Standard deviation \\
\hline Body weight $(\mathrm{kg})$ & 44.68 & \pm 5.76 \\
Lenght $(\mathrm{cm})$ & 78.87 & \pm 5.64 \\
Volume $(\mathrm{mL})$ & 17.87 & \pm 2.30 \\
PVI $(\mathrm{mL})$ & 17.91 & \pm 3.62 \\
Sap0 $(\mathrm{mmHg})$ & 11.12 & \pm 4.16 \\
Sapmax $(\mathrm{mmHg})$ & 101.87 & \pm 22.54
\end{tabular}

correlation, $r>0.4<0.69$ demonstrates a moderate correlation and $r>0.7<1.0$ evidences a strong correlation.

The parameters that presented a strong correlation $(r>0.7<1.0)$ were: volume and weight, PVI and weight, and volume and PVI (Table 4).

Based on the correlation between Weight and PVI displayed in Table 4, a linear regression graph of these variables was obtained as well as the linear equation $(Y=\alpha+x \beta)$, which are shown in Figure 2.

As shown in Figure 2, by utilizing the linear equation obtained, it is possible to estimate the PVI values according to the body weight, thus fixing the value of maximum subarachnoid pressure. From this, in turn, the volume necessary to achieve this value can be calculated, that is, the dose of contrast medium to carry out the myelography exam without surpassing the pre-stipulated subarachnoid pressure. The estimates of PVI, contrast volume and dose for a determinate weight range are displayed in Table 5, for the maximum subarachnoid pressure values of 40,50 and $60 \mathrm{mmHg}$.

\section{DISCUSSION}

The intracranial pressure of sheep, when previously measured with an intra-parenchymal catheter, produced baseline values from 7 to $15 \mathrm{mmHg}$ (mean of $11 \mathrm{mmHg}$ ), which is considered normal for the species (Mousavi et al. 2001). The present study found elevated SaP values correlated with those of ICP, which corroborates other studies (Arany-Tóth et al. 2012). However, in this study healthy sheep was used and the ioexol contrast

Table 4. Pearson correlation between the variables: body weight, length, contrast volume and pressure volume-index

(PVI) exposing the $r$ value of the experimental model of ovine submitted to lumbar myelography and subarachnoid pressure measurement

\begin{tabular}{lcccc}
\hline & Body weight & Lenght & Volume & PVI \\
\hline Body weight & 1 & & & \\
Lenght & 0.491 & 1 & & \\
Volume & $1^{* \partial}$ & 0.491 & 1 & \\
PVI & $0.756^{* \partial}$ & 0.410 & $0.756^{* \partial}$ & 1
\end{tabular}

$£=$ Weak correlation $\mathrm{r}<0.39, \S=$ moderate correlation $\mathrm{r}>0.4<0.69, \partial$ $=$ strong correlation $r>0.7<1.0$; ${ }^{*}$ significative values $5 \%$, in these the superscript symbol represents the strength of the correlation.

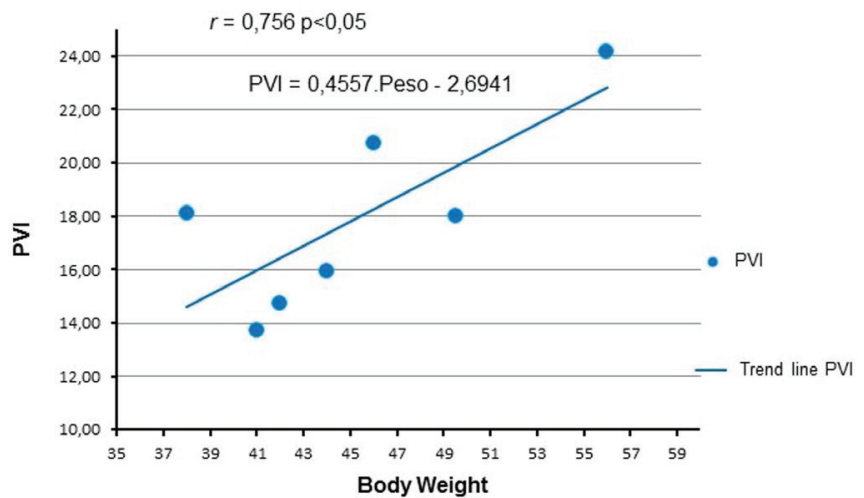

Fig.2. Pressure-volume indexes (PVI) graphically plotted against body weight. The trend line obtained by linear regression, showing the resulting straight-line equation, as well as the Pearson and $\mathrm{p}$. 
was inject by means of lumbar puncture, different from the Arany-Tóth et al. $(2012,2013)$ methodology.

Even though ICP values were considered normal for the species, it is necessary to analyze these data with caution, once the anesthetic protocol can alter ICP (Ivan \& Choo 1982). The baseline $\mathrm{EtCO}_{2}$ values (averaged $41 \mathrm{mmHg}$ ) represents a level that does not promote encephalic vasodilation and consequent ICP increasing (Ivan \& Choo 1982). The importance of ventilator support methodology was demonstrated in a study on the ICP dynamic, since the lack of $\mathrm{CO}_{2}$ pressure control will lead to an augmentation of ICP (Armitage-Chan et al. 2007). Dogs anesthetized with Propofol infusion and maintained in spontaneous respiration achieved a higher mean ICP than propofol-infusion-anesthetized dogs kept under controlled ventilation, while those that remained with spontaneous respiration presented higher $\mathrm{EtCO}_{2}$ levels (Nishimori et al. 2006).

Volatile anesthetic agents influenced ICP in a dosedependent pattern, disturbing compensatory mechanisms or by encephalic vasodilatation, leading to an increased cephalic volume and interstitial edema (Ivan \& Choo 1982). In a study of dogs anesthetized with $1.4 \%$ (FeISO) Isoflurane, there was no significant increase in cerebral blood flow, maintaining their compensatory mechanisms (Lopes et al. 2011). In the present study, the mean Isoflurane values at M0 were 1.08\%, causing few or no changes on ICP values, considered normal for the species.

ICP is dependable on components of skull, such as encephalic parenchyma, CSL and blood. Changes of any of these elements might, potentially, alter ICP (Artru 1984). In the present study, a statistically significant increase of SaP was observed at M1 and M2. The M1 value was 9.15 -fold greater than M0, which was the top level reached during the introduction of contrast medium into the subarachnoid space. However, the rise of M2 in relation to M0 was 3.87 times, where M2 represents two minutes after contrast application. The subsequent moments did not differ from the baseline SaP values. These findings corroborate another study (Arany-Tóth et al. 2012) in which, after cisternal injection of contrast, there was a 7.7-fold increase of subarachnoid pressure and subsequent reduction two minutes after application, remaining 4.4 times greater than the baseline values.

Nevertheless, it was expected for our study to find lower SaP values, considering that one of the compensatory mechanisms is the displacement of CSL to the projections of dural sac (Löfgren \& Zwetnow 1973); the lumbar application would provide more meningeal projections to allocate the volume injected.

SaP at M3 and M4 did not differ in relation to the initial moment. These findings are resultant from encephalic complacency, which is attributable to three factors: displacement and reabsorption of CSL, exit of venous blood and arrival of arterial blood. These compensatory mechanisms make the ICP values return to the baseline level (Löfgren \& Zwetnow 1973).

Through SaP values it was possible to calculate CPP, by means of the following formula: $\mathrm{CPP}=\mathrm{MAP}$ - ICP . A significant difference between $\mathrm{M} 0$ and $\mathrm{M} 1$, and between $\mathrm{M} 1$ in relation to M2, M3 and M4 was observed. The abrupt ICP increase at M1 indicates that $100 \%$ of the animals showed values below $60 \mathrm{mmHg}$, and $50 \%$ had a mathematically negative CPP, presumably showing severe ischemia. Pressures below $60 \mathrm{mmHg}$ represent a decrease in encephalic blood supply (Ivan \& Choo 1982), followed by cerebral hyperemia, decreased $\mathrm{pO}_{2}$ (partial pressure of oxygen) in cerebral venous blood,

Table 5. Relation of pressure volume-index (PVI) values, body weight, contrast volume and dose required to increase maximal subarachnoid pressure (SaPmax) at 40, 50 and $60 \mathrm{mmHg}$ as a theoretical limit of pressure of the experimental model of ovine submitted to lumbar myelography and check of subarachnoid pressure

\begin{tabular}{|c|c|c|c|c|c|c|c|}
\hline \multirow{2}{*}{$\frac{\text { Body weight }}{\mathrm{kg}}$} & \multirow{2}{*}{$\begin{array}{c}\text { PVI } \\
\mathrm{mL}\end{array}$} & \multicolumn{2}{|c|}{ SaPmax 40mmHg } & \multicolumn{2}{|c|}{ SaPmax 50mmHg } & \multicolumn{2}{|c|}{ SaPmax 60mmHg } \\
\hline & & $\mathrm{mL}$ & $\mathrm{mL} / \mathrm{kg}$ & $\mathrm{mL}$ & $\mathrm{mL} / \mathrm{kg}$ & $\mathrm{mL}$ & $\mathrm{mL} / \mathrm{kg}$ \\
\hline 30 & 10.98 & 6.10 & 0.20 & 7.17 & 0.24 & 8.04 & 0.27 \\
\hline 34 & 12.80 & 7.12 & 0.21 & 8.36 & 0.25 & 9.37 & 0.28 \\
\hline 36 & 13.71 & 7.62 & 0.21 & 8.95 & 0.25 & 10.04 & 0.28 \\
\hline 40 & 15.53 & 8.64 & 0.22 & 10.14 & 0.25 & 11.37 & 0.28 \\
\hline 42 & 16.45 & 9.14 & 0.22 & 10.74 & 0.26 & 12.04 & 0.29 \\
\hline 44 & 17.36 & 9.65 & 0.22 & 11.33 & 0.26 & 12.71 & 0.29 \\
\hline 46 & 18.27 & 10.16 & 0.22 & 11.93 & 0.26 & 13.37 & 0.29 \\
\hline 54 & 21.91 & 12.18 & 0.23 & 14.31 & 0.26 & 16.04 & 0.30 \\
\hline 56 & 22.83 & 12.69 & 0.23 & 14.90 & 0.27 & 16.71 & 0.30 \\
\hline 58 & 23.74 & 13.20 & 0.23 & 15.50 & 0.27 & 17.38 & 0.30 \\
\hline 60 & 24.65 & 13.70 & 0.23 & 16.09 & 0.27 & 18.04 & 0.30 \\
\hline
\end{tabular}


increased $\mathrm{pCO}_{2}$ (partial pressure of carbon dioxide), as well as lactate and pyruvate in the venous blood, and decreased blood pH (Czosnyka \& Citerio 2012).

Critical CPP is an important concept because it is the threshold to ensure adequate cerebral perfusion, under diverse clinical conditions (Kjällquist et al. 1969). There are experimental differences in critical CPP due to the obtainment methods; by decreased arterial pressure $(50 \mathrm{mmHg})$ or increased ICP (30 mmHg) (Bragin et al. 2014). Nevertheless, they observed that this difference is caused by a false cerebral blood flow, whereas in fact the vascular cerebral self-regulation is lost and the cerebral perfusion is unsatisfactory at values similar to when reduced arterial pressure occurs (Miller et al. 1972). These data corroborate the presumption that the animals of the present experiment suffered cerebral ischemia during lumbar myelography and the majority of them two minutes after the injection of contrast medium.

In a recent study, the prognosis was evaluated in human patients with cranial traumatism, and a better result was observed in patients with CPP higher than $10 \mathrm{mmHg}$ (Khalili et al. 2016). However, these patients maintained low CPP values for long periods (Petkus et al. 2016). In the present study the animals remained with pressures below the ideal level for a short period of time, about four minutes. In a retrospective study of human patients diagnosed with brain death, 87.5\% of them exhibited negative CPP for a mean duration of 13 hours (Petkus et al. 2016).

Alterations in MAP may interfere with CPP values when variations exceed the levels of self-regulation, i.e., arterial pressures below $50 \mathrm{mmHg}$ or greater than $150 \mathrm{mmHg}$ (Nishimori et al. 2006). In our study, MAP remained within physiological limits at all moments studied, and it cannot be attributed to ICP variations.

When ICP increases and CPP and encephalic blood flow are affected, an increase in blood pressure begins, through vasoconstriction and diversion of blood flow from the splanchnic bed, in an attempt to maintain encephalic tissue perfusion. MAP will continue to increase until cerebral perfusion rises. In case of an exaggerated increase in MAP, reflex bradycardia occurs, in order to avoid damage resulting from hypertension (Kirkeby et al. 1995, Fodstad et al. 2006, Armitage-Chan et al. 2007). There was a significant increase in the values of MAP in M1 when compared to other moments, attributing the drastic reduction observed in CPP with impaired encephalic blood flow. The reduction indicated by our data in the following moments is consistent with the reestablishment of cerebral blood flow and the progressive return to baseline values of SaP and PPC.

Considering the PVI obtained in the present study, on average $17.91 \mathrm{~mL}$ is required to elevate the subarachnoid pressure by 10 times. This value differs from other previous study $(7 \mathrm{~mL})$ (Arany-Tóth et al. 2012), however they used dogs. It is known that the PVI can differ among species and individuals as a result of intracranial volume (Kalmar et al. 2005). Additionally, we used the lumbar route, which produces elevation of the PVI value by increasing the buffering volume, as it has been already demonstrated by other authors (Salih et al. 2006). In other words, the lumbar introduction of contrast medium utilizes a lower reserve volume of the intracranial system, utilizing the entire complacency capacity of the cranial-spinal axis, thus demanding a greater quantity of contrast medium to produce ICP changes.
The SaPmax values produced a mean of $101.87 \mathrm{mmHg}$, a considerably high value but close to $70 \mathrm{mmHg}$ obtained by others studying dogs (Arany-Tóth et al. 2012). The total volume of contrast medium and the velocity of infusion, presumably, explains these high SaPmax values in our study. Thus, more studies are necessary to better understand the behavior of ICP and PVI in sheep.

Pearson's correlation test demonstrated a strong correlation $(r>0.7<1.0)$ between PVI/Weight and PVI/Volume, an expected result given that the PVI formula is directly proportional to the volume infused, which is relative to the weight of the animal. However, it was not significantly correlated with the length of the animal. In children, the PVI can be estimated through the columnar length and head circumference (Gray \& Rosner 1987). In the present study, despite the uniformity of the sample, it was shown that this variable was not correlated.

The PVI for each animal was submitted to a linear regression equation based on its correlation with the weight, generating a linear equation $(Y=\alpha+x \beta)$, in which $\mathrm{PVI}=0.4557 \times$ Weight -2.6941 ; considering this, $\mathrm{PVI}$ can be estimated for diverse weights of healthy sheep. From this point the volume necessary for a supposed ICP increase can be measured specifically.

The recommended contrast medium doses, following an estimate of fixed values of SaP, varied from 0.23 to $0.3 \mathrm{~mL} /$ $\mathrm{kg}$ considering weights and pre-determined pressures. These values are lower than those used $(0.4 \mathrm{~mL} / \mathrm{kg})$ and considerably lower than those used by Mageed et al. (2014), who perform myelotomographies on healthy sheep using $0.45 \mathrm{~mL} / \mathrm{kg}$, and achieved good image resolution.

In this study the quality of the radiographic image was not evaluated; however, it would be useful to check the ideal dose of contrast medium in order to get a good image without severe SaP changes.

Post-myelography side effects such as epileptic crises and worsening of the neurological state have been demonstrated in dogs, and they are directly influenced by the total volume of contrast medium injected. Eight milliliters of contrast medium have been recommended as the maximum volume in dogs (Costa et al. 2011) and this recommendation has been used for all vertebral segments and routes of injection. Comparing the data from the present study with those from others (Arany-Tóth et al. 2012), a relevant difference in the estimated maximum dose is observed between the lumbar and cisterna magna routes. Therefore, the maximum volume of $8 \mathrm{~mL}$ for myelography in dogs must be questioned.

According to the results of this research and considering the available literature, the initial hypothesis was confirmed. There were no significant changes in cerebral perfusion pressure and pressure volume index, when performing the lumbar puncture myelography. However, slight subarachnoid pressure changes were detected.

Since the dog (and cat) was the target species when this experiment was planned, using the healthy sheep is the most important limitation of the study, that was chosen due to ethical issues. However, we believe that the data can be extrapolated since more and more sheep are used as an experimental model. Other important limitation is the fact that intracranial pressure was assessed indirectly. Finally, comparisons between lumbar and cisternal myelography would have provided more valuable information. 


\section{CONCLUSIONS}

Lumbar myelography leads to a significant increased subarachnoid pressure (SaP, mean of $101.87 \mathrm{mmHg}$ ), returning to baseline values four minutes after the injection. Under the methodology employed, the pressure volume-index (PVI) value for the ovine species is $17.91 \mathrm{~mL}$.

Despite of the effect on subarachnoid pressure, lumbar myelography can be considered safe in sheep.

Conflict of interest statement.- The authors have no competing interests.

\section{REFERENCES}

Arany-Tóth A., Csébi P., Reiczigel J. \& Németh T. 2012. Pressure-volume index-based volume calculation of contrast medium for atlantooccipital myelography in dogs. Vet. Radiol. Ultrasound 53(4):430-436. <https://dx.doi.org/10.1111/j.1740-8261.2012.01935.x><PMid:22548310>

Arany-Tóth A., Csébi P., Reiczigel J., Sére V. \& Németh T. 2013. Subarachnoid pressures and cardiorespiratory parameters during cisternal myelography in isoflurane anaesthetized dogs. Vet. Anaesth. Analg. 40(4):390-398. <https://dx.doi.org/10.1111/vaa.12019><PMid:23438043>

Armitage-Chan E.A., Wetmore L.A. \& Chan D.L. 2007. Anesthetic management of the head trauma patient. J. Vet. Emerg. Crit. Care 17(1):5-14. <https://dx.doi.org/10.1111/j.1476-4431.2006.00194.x>

Artru A.A.1984. Relationship between cerebral blood volume and CSF pressure during anesthesia with isoflurane or fentanyl in dogs. Anesthesiology 60(6):575-579.<https://dx.doi.org/10.1097/00000542-198406000-0001> <PMid:6731913>

Avezaat C.J., Van Eijndhoven J.H. \& Wyper D.J. 1979. Cerebrospinal fluid pulse pressure and intracranial volume-pressure relationships. J. Neurol. Neurosurg. Psych. 42(8):687-700. <https://dx.doi.org/10.1136/ jnnp.42.8.687><PMid:490174>

Barone G., Ziemer L.S., Shofer F.S. \& Steinberg S.A. 2002. Risk factors associated with development of seizures after use of iohexol for myelography in dogs: 182 cases (1998). J. Am. Vet. Med. Assoc. 220(10):1499-1502. <https://dx.doi.org/10.2460/javma.2002.220.1499><PMid:12018377>

Bragin D.E., Statom G.L., Yonas H., Dai X. \& Nemoto E.M. 2014. Critical cerebral perfusion pressure at high intracranial pressure measured by induced cerebrovascular and intracranial pressure reactivity. Crit. Care Med. 42(12):2582-2590.<https://dx.doi.org/10.1097/CCM.0000000000000655> <PMid:25289933>

Costa R.C., Parent J.M. \& Dobson H. 2011. Incidence of and risk factors for seizures after myelography performed with iohexol in dogs: 503 cases (2002-2004). J. Am. Vet. Med. Assoc. 238(10):1296-1300. <https://dx.doi. org/10.2460/javma.238.10.1296><PMid:21568775>

Czosnyka M. \& Citerio G. 2012. Brain compliance: the old story with a new 'et cetera'. Intensive Care Med. 38(6):925-927. <https://dx.doi.org/10.1007/ s00134-012-2572-6><PMid:22527086>

Fodstad H., Kelly P.J. \& Buchfelder M. 2006. History of the cushing reflex. Neurosurgery 59(5):1132-1137. <https://dx.doi.org/10.1227/01. NEU.0000245582.08532.7C > <PMid:17143247>

Gray W.J. \& Rosner M.J. 1987. Pressure-volume index as a function of cerebral perfusion pressure Part 1: the effects of cerebral perfusion pressure changes and anesthesia. J. Neurosurg. 67(3):369-376. <https://dx.doi. org/10.3171/jns.1987.67.3.0369> <PMid:3612269>

Ivan L.P. \& Choo S.H. 1982. A comparative study of epidural and cisternal pressure in dogs. J. Neurosurg. 57(4):511-514.<https://dx.doi.org/10.3171/ jns.1982.57.4.0511><PMid:7108601>

Kalmar A.F., Van Aken J., Caemaert J., Mortier E.P. \& Struys M.P. 2005. Value of Cushing reflex as warning sign for brain ischaemia during neuroendoscopy. Brit. J. Anaesth. 94(6):791-799. <https://dx.doi.org/10.1093/bja/aei121> $<$ PMid:15805143>

Khalili H., Sadraei N., Niakan A., Ghaffarpasand F. \& Sadraei A. 2016. Role of intracranial pressure monitoring in management of patients with severe traumatic brain injury; results of a large level I trauma center in Southern Iran. World Neurosurg. 94:120-125. <https://dx.doi.org/10.1016/j. wneu.2016.06.122><PMid:27392896>

Kirkeby O.J., Rise I.R., Nordsletten L., Skjeldal S. \& Risøe C. 1995. Cardiovascular response to blood loss during high intracranial pressure. J. Neurosurg. 83(6):1067-1071. <https://dx.doi.org/10.3171/jns.1995.83.6.1067> $<$ PMid:7490622>

Kishimoto M., Yamada K., Ueno H., Kobayashi Y. \& Wisner E.R. 2004. Spinal cord effects from lumbar myelographic injection technique in the dog. J. Vet. Med. Sci. 66(1):67-69. <https://dx.doi.org/10.1292/jvms.66.67> $<$ PMid:14960814>

Kjällquist A., Siesjö K.B. \& Zwetnow N. 1969. Effects of increased intracranial pressure on cerebral blood flow and on cerebral venous $\mathrm{PO}_{2}, \mathrm{pCO}_{2}, \mathrm{pH}$, lactate and pyruvate in dogs. Acta Physiol. Scand. 75(3):267-275. <https:// dx.doi.org/10.1111/j.1748-1716.1969.tb04380.x><PMid:5790219>

Löfgren J. \& Zwetnow N.N. 1973. Cranial and spinal components of the cerebrospinal fluid pressure-volume curve. Acta Neurol. Scand. 49(5):575585. <https://dx.doi.org/10.1111/j.1600-0404.1973.tb01331.x> $<$ PMid:4770653>

Lopes P.C.F., Nunes N., Dias L.G.G.G., Pereira Neto G.B., Almeida R.M., Souza A.L.G. \& Belmonte E.A. 2011. Bispectral index in dogs with high intracranial pressure, anesthetized with propofol and submitted to two levels of FiO2. Arq. Bras. Med.Vet.Zootec. 63(6):1359-1367. <https://dx.doi.org/10.1590/ S0102-09352011000600012>

Marmarou A., Shulman K. \& Rosender M.A. 1978. Nonlinear analysis of the cerebrospinal fluid system intracranial pressure dynamics. J. Neurosurg. 48(3):332-344. <https://dx.doi.org/10.3171/jns.1978.48.3.0332> <PMid:632857>

Maset A.L., Marmarou A., Ward J.D., Choi S., Lutz H.A., Brooks D., Moulton R.J., DeSalles A., Muizelaar J.P. \& Turner H. 1987. Pressure-volume index in head injury. J. Neurosurg. 67(6):832-840.<https://dx.doi.org/10.3171/ jns.1987.67.6.0832><PMid:3681422>

Miller J.D., Stanek A. \& Langfitt T.W. 1972. Concepts of cerebral perfusion pressure and vascular compression during intracranial hypertension. Progress Brain Res. 35:411-432. <https://dx.doi.org/10.1016/S00796123(08)60102-8><PMid:5009562>

Mousavi M., Kolonja A., Schaden E., Gäbler C., Ehteshami J.R. \& Vécsei V. 2001. Intracranial pressure-alterations during controlled intramedullary reaming of femoral fractures: an animal study. Injury 32(9):679-682. <https://dx.doi. org/10.1016/s0020-1383(01)00048-1><PMid:11600112>

Nishimori C.T., Paula D.P., Moraes P.C., Conceição E.D.V., Carareto R., Nunes N. \& Freitas P.M.C. 2006. Alterações hemodinâmicas e intracranianas em cães com hemorragia aguda, anestesiados com Isoflurano. Arq. Bras. Med. Vet. Zootec. 58(6):1048-1056.<https://dx.doi.org/10.1590/S010209352006000600012>

Petkus V., Krakauskaitè S., Preikšaitis A., Ročka S., Chomskis R. \& Ragauskas A. 2016. Association between the outcome of traumatic brain injury patients and cerebrovascular autoregulation, cerebral perfusion pressure, age, and injury grades. Medicina 52(1):46-53. <https://dx.doi.org/10.1016/j. medici.2016.01.004> <PMid:26987500>

Robertson I. \& Thrall D.E. 2011. Imagind dogs with suspected disc herniation: pros and cons of myelography, computed tomography, and magnetic resonance. Vet. Radiol. Ultrasound 52(1 Supl.1):S81-S84.<https://dx.doi. org/10.1111/j.1740-8261.2010.01788.x><PMid:21392160>

Salih F., Holtkamp M., Brandt S.A., Hoffmann O., Masuhr F., Schreiber S., Weissinger F., Vajkoczy P. \& Wolf S. 2016. Intracranial pressure and cerebral perfusion pressure in patients developing brain death. J. Crit. Care 34:1-6. <https://dx.doi.org/10.1016/j.jcrc.2016.03.009> <PMid:27288600>

Silva Jr J.C. 2006. Efeitos de solução salina hipertônica e manitol em coelhos com hipertensão intracraniana aguda. Master's Thesis in Neuropsychiatry Concentration area in Experimental Neuroscience, Centro de Ciências da Saúde, Universidade Federal de Pernambuco, Recife, PE. 95p.

Siqueira E.G.M., Rahal S.C., Vassalo F.G., Araújo F.A.P. \& Agostinho F.S. 2013. Trauma cranioencefálico em pequenos animais. Vet. Zootec. 20(Edição Comemorativa):112-123. 